\title{
TCOM \\ Mission Mosquito: building and expanding an international network for innovation in health communication
}

\section{Tanya M. Maslak, Kia Henry, Natasha Sadoff, David Maurice Jones, Joshua L. Glasser and Amy Leibrand}

\begin{abstract}
The Mission Mosquito Information Sharing Program (ISP), a collaboration between the U.S. Department of State and Battelle Memorial Institute, is a public diplomacy effort to build and expand an international network of health communicators to increase engagement on mosquito-borne disease. Nineteen professionals from countries experiencing mosquito-borne diseases engaged in a two-week multi-directional information exchange across the United States in May 2018. Program alumni applied knowledge and tools from the ISP in follow-on projects and public outreach campaigns in their home countries. This paper summarizes the ISP and lessons learned, and highlights a science communication case study examining skills and understanding gained.
\end{abstract}

Keywords

DOI

Background
Health communication; Professionalism, professional development and training in science communication; Science communication in the developing world

https://doi.org/10.22323/2.19030801

Submitted: 16th December 2019

Accepted: 28th May 2020

Published: 22nd June 2020

Vector-borne diseases account for $17 \%$ of all infectious diseases globally, and more than $50 \%$ of the world's population is estimated to be at risk for infection [World Health Organization (WHO), 2017; World Health Organization (WHO), 2014]. These diseases disproportionally affect tropic and sub-tropic populations where favourable mosquito breeding and growth conditions exist, such as high humidity, precipitation, and heat [Gage et al., 2008], and where capacity for prevention or response may be low. Nonetheless, many innovative health communication and prevention measures to protect populations against Zika and other mosquito-borne diseases have been implemented in high-burden regions.

Since 2015, there have been more than 246,000 confirmed cases of Zika virus infections in the Americas and 87 countries and territories worldwide have reported Zika transmission [Pan American Health Organization (PAHO), 2019; 
World Health Organization (WHO), 2019a]. In reality, these numbers are likely much higher due to underreporting as a result of asymptomatic infections, inadequate access to healthcare, and poor surveillance or reporting frameworks [Siedner, Ryan and Bogoch, 2018; Grubaugh et al., 2019; Cardenas, Paternina-Caicedo and Salvatierra, 2019]. While Zika infection rates have rapidly declined, recent localized outbreaks highlight the need for continued communication with the public about prevention of all mosquito-borne diseases [World Health Organization (WHO), 2019b]. Responding to viruses transmitted by mosquitoes, such as Zika, dengue, chikungunya, yellow fever, and others, are often a challenge to address due to the pressure that outbreaks place on health resources, difficulty engaging communities, insufficient regional expertise and capacity, and complicated logistics [Maciel-de-Freitas et al., 2012; Horstick et al., 2010]

Research regarding health communication in affected countries emphasizes the need for accurate and efficient communication between public officials, medical personnel, and the public, including the need to tailor dissemination methods to communities and provide culturally relevant information [McNeish et al., 2019; Brittain et al., 2019].

Through their Global Health Security Agenda and public health diplomacy efforts to improve international readiness to prevent, detect, and respond to infectious diseases, the U.S. Department of State (DOS) - both at headquarters and via their global network of U.S. diplomatic and consular posts - strive to build global capacity to address such concerns. Recent public diplomacy efforts led by the Bureau of Oceans and International Environmental and Scientific Affairs (OES) emphasized programming on Zika and other mosquito-borne infectious diseases, including a series of activities under the "Mission Mosquito" portfolio. Mission Mosquito activities encompassed citizen science and innovation-inspiring tech camps, professional information exchange, and other forms of cultural and scientific outreach. As part of this programming, DOS, in cooperation with Battelle Memorial Institute (Battelle) initiated the Mission Mosquito Information Sharing Program (ISP), which ran from October 2017 to August 2019. The overall objective of the Mission Mosquito ISP was to build capacity for a self-sustaining international network of community leaders and trusted public figures to drive innovative public engagement and locally appropriate communication strategies.

The Information Sharing Program (ISP)

\section{Mission Mosquito ISP Objectives}

The scope for the Mission Mosquito ISP included two main objectives. The first objective was to equip participants with technical information, data, and communication strategies. This was accomplished via participation in a two-week multi-directional information exchange across the United States in May 2018 with targeted engagement between program participants and selected subject matter experts, as well as a public-private stakeholder forum held in Washington, DC. The second objective was to build a self-sustaining international network of program alumni. This was accomplished through a small grants competition initiating public outreach campaigns building upon the information and tools gained through the ISP, as well as a communication network including the use of social media and other forms of electronic communication to maintain continued engagement post-ISP. 


\section{Mission Mosquito ISP Participants}

To identify participants for the Mission Mosquito ISP, DOS sent a call for nominations in December 2017 to U.S. Embassies in countries experiencing Zika outbreaks, countries where Zika is endemic, and countries that are vulnerable to future spread of the virus. The nomination process sought to identify community leaders such as journalists, science writers, health practitioners, scientists, health educators, museum curators and similar professionals who have regular public contact and can broaden the professional network that seeks to increase awareness of and prevent mosquito-borne disease. Prioritization criteria for selection included professionals with existing responsibility for science or health communication, particularly in vector-borne disease prevention campaigns and outreach, with a demonstrated commitment to their field, and innovative approaches to public engagement.

The process resulted in 56 nominations from more than 25 countries from the Western Hemisphere, Africa, East Asia, the Pacific, and South/Central Asia. DOS selected twenty nominees, and ultimately 19 participants representing the countries in Figure 1 traveled to the United States to participate in the information exchange. Participants included nine women and seven emerging professionals (i.e., less than forty years old) from Ministries of Health, local non-profit organizations (NGOs), media outlets, museums, and other organizations.

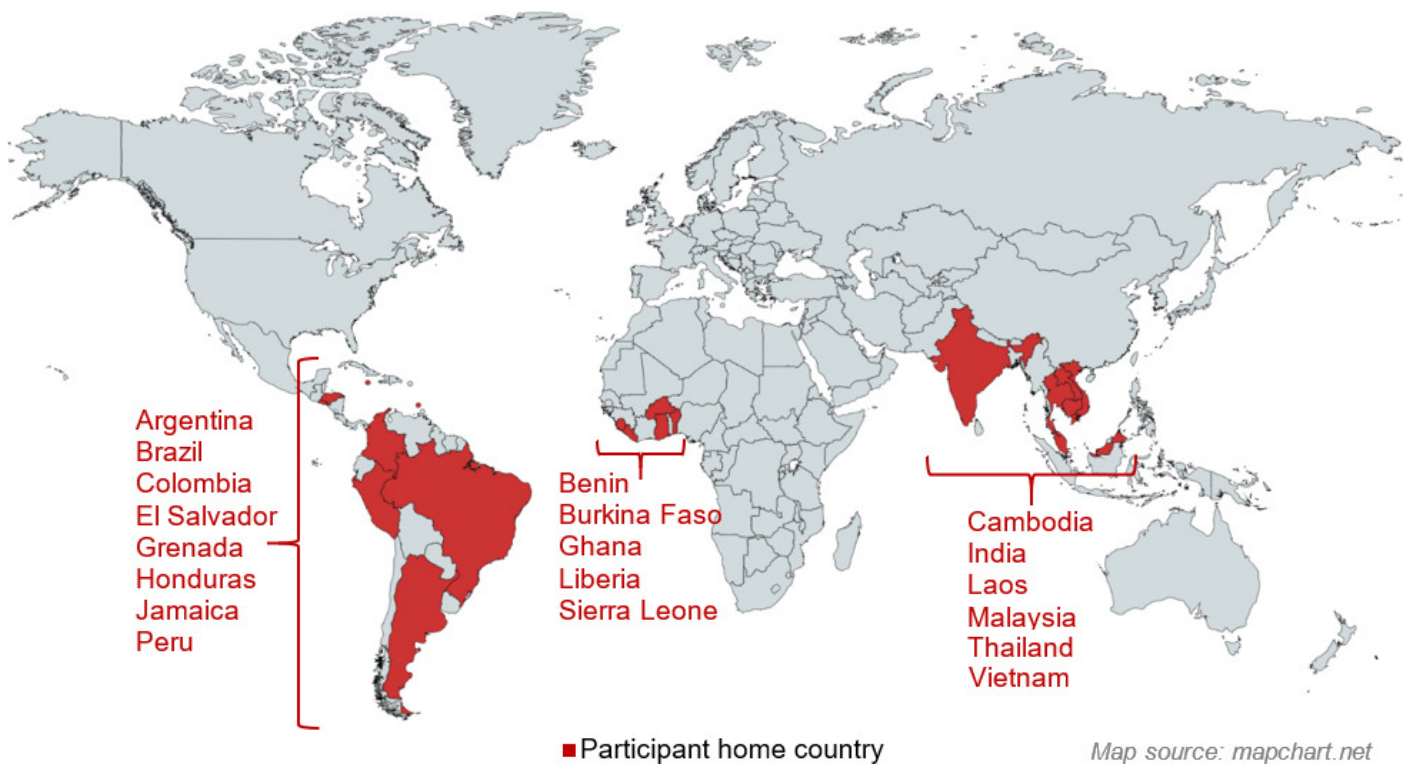

Figure 1. Countries represented by the Mission Mosquito Information Sharing Program.

\section{Mission Mosquito ISP Information Exchange: Overview of Stops and Themes}

The purpose of the ISP information exchange was to equip participants with technical information, data, and communication strategies via targeted engagement between program participants and selected subject matter experts. The ISP was designed to elucidate best practices for health communication, as well as introduce topics critical for understanding the complexities of mosquito-borne disease necessary to design and employ informed and tailored communication efforts. Due 
to the professional backgrounds of the participants and the limited duration of the exchange, topics of discussion were focused on predetermined issues: vector control, citizen science, public-private partnerships, and risk communication. The topical focus, coupled with an applied learning approach, equipped participants with tools and strategies for participatory, informal learning or citizen science on a local level that could be utilized upon return to their communities.

The cities selected for the two-week information exchange were chosen based on their proximity to U.S. government stakeholders or their direct experience with the Zika outbreak response. The information exchange included stops in Atlanta, Georgia; Fort Collins, Colorado; South Florida; and Washington, DC, and was held from 6-18 May 2018. Table 1 below provides an overview of activities at each stop.

\section{Impacts on Mission Mosquito ISP Participants}

ISP facilitators implemented an evaluation process throughout the course of the program to ensure participant benefit from the ISP and maximize engagement to the extent within our control. As appropriate and possible, the team adjusted schedules, logistics, and other program factors to demonstrate responsiveness to participant input throughout the ISP.

In addition to organic, informal feedback noted during conversations with participants throughout the ISP, Battelle conducted a more formalized mid- and post-ISP evaluation to assess participant satisfaction and perceived benefit. In an effort to minimize the burden on participants during the ISP, while also maximizing responsiveness, printed versions of the evaluation forms were distributed to participants at the end of week 1 and 2 for the mid- and post-evaluations, respectively. Participants were given at least two days to complete and submit these forms, which were collected by the ISP facilitators prior to participant travel back to their home countries. Evaluation forms were comprised of comparative rating scale questions, including Likert scales, which sought to gauge participant satisfaction with the content and subject matter experts, depth of discussions, and relevance and benefit to their professional roles. Additional open-ended questions asked participants about their least and most favored parts of the program, and recommendations for improvements. Responses were analyzed by thematic coding to determine common themes. Response rates were $79 \%$ and $95 \%$ for the mid- and post-ISP evaluations, respectively.

Mid-program evaluation results showed many individuals appreciated case examples and scientific evidence provided, as well as the ability to share information with scientific experts and other participants. A few participants reported that some presentations were overly technical and should have been revised for the audience. Battelle coordinators made modifications to adjust the remaining activities to better align with participants' preferences.

To further gauge post-ISP impact of resources provided, relationships established, and overall application of program content at participants' jobs over time, Battelle conducted virtual "spotlight interviews" that consisted of an electronic form of open-ended questions distributed by email several months after completion of the ISP. Questions focused on reflections on the ISP, including key takeaways or 
Table 1. Overview of ISP stop locations, themes, and highlights.

\begin{tabular}{|c|c|c|}
\hline Location & Theme & Highlights \\
\hline Atlanta, GA & $\begin{array}{l}\text { Crisis and } \\
\text { emergency } \\
\text { risk commu- } \\
\text { nications }\end{array}$ & $\begin{array}{l}\text { - Program kick-off, including introductions and discussion of participant goals } \\
\text { - Training on U.S. Centers for Disease Control and Prevention (CDC) Crisis and Emer- } \\
\text { gency Risk Communication, establishing a baseline for exploring communications } \\
\text { throughout the program } \\
\text { - Met with CDC Office of Global Health, Communications, and Zika outbreak response } \\
\text { staff } \\
\text { - Toured the CDC Emergency Operations Center and Joint Information Center, where } \\
\text { messaging is developed and disseminated during emergencies } \\
\text { - Guided tour of the David J. Sencer museum, a venue for increasing awareness on } \\
\text { public health topics and events }\end{array}$ \\
\hline $\begin{array}{l}\text { Fort Collins, } \\
\text { CO }\end{array}$ & $\begin{array}{l}\text { Data col- } \\
\text { lection and } \\
\text { surveillance, } \\
\text { mosquito } \\
\text { control, and } \\
\text { pesticide } \\
\text { resistance }\end{array}$ & $\begin{array}{l}\text { - Met with researchers from Colorado State University (CSU), Fort Collins, and CDC's } \\
\text { National Center for Emerging Zoonotic Infectious Diseases to learn about guidelines } \\
\text { for sustainable mosquito control programs, cutting edge science to improve under- } \\
\text { standing of Zika virus detection and transmission, and challenges of insecticide res- } \\
\text { istance } \\
\text { - Toured the CSU insectary to witness mosquito research in a laboratory setting } \\
\text { - Visited the local National Ecological Observatory Network (NEON) site to explore } \\
\text { collection of environmental data related to health outcomes, including mosquito trap- } \\
\text { ping techniques }\end{array}$ \\
\hline $\begin{array}{l}\text { South } \\
\text { Florida, } \\
\text { including } \\
\text { Fort } \\
\text { Lauderdale, } \\
\text { Miami, and } \\
\text { Wynwood }\end{array}$ & $\begin{array}{l}\text { Local } \\
\text { response }\end{array}$ & $\begin{array}{l}\text { - Met with local governmental officials and other stakeholders to discuss socio- } \\
\text { geographic factors impacting Zika response in the U.S., and epidemiological, emer- } \\
\text { gency management, public works, and vector control aspects of local response } \\
\text { - Toured the Wynwood neighborhood of Miami, epicenter for Zika response in the } \\
\text { U.S., to hear about challenges faced with public perceptions and impacts on local } \\
\text { businesses and tourism } \\
\text { - Participated in Wolbachia-infected mosquito release and discussed the need for com- } \\
\text { munity education prior to and during release efforts so that the public understands } \\
\text { the program and potential benefits, and concerns can be addressed }\end{array}$ \\
\hline $\begin{array}{l}\text { Washington, } \\
\text { DC }\end{array}$ & $\begin{array}{l}\text { Innovative } \\
\text { tools to } \\
\text { engage com- } \\
\text { munities in } \\
\text { mosquito } \\
\text { control and } \\
\text { disease } \\
\text { prevention }\end{array}$ & $\begin{array}{l}\text { - Met with DOS to discuss alumni exchange resources } \\
\text { - Demoed the GLOBE Mosquito Habitat Mapper, a citizen science tool developed by } \\
\text { NASA and other scientists available via mobile app } \\
\text { - Introduced to NASA data products providing environmental conditions that may } \\
\text { predict mosquito breeding sites using models and precipitation, soil moisture, land } \\
\text { cover and temperature data } \\
\text { - Attended the launch of the Smithsonian Institution's Outbreak: Epidemics in a Connec- } \\
\text { ted World exhibit } \\
\text { - Participated in the Mission Mosquito Global Health Security and Public Communic- } \\
\text { ation Forum to discuss innovative tools for communication, such as citizen science, } \\
\text { art, and video. ISP participants shared their experiences in conducting health com- } \\
\text { munication activities through presentations during plenary and breakout sessions }\end{array}$ \\
\hline
\end{tabular}


experiences from the ISP, the personal or professional significance of the program, and the influence of the ISP on participants upon returning home. Additional questions sought to understand how participants were using ISP skills to form new partnerships, develop new programming in their professional roles, or how they may have shared the information gathering during the ISP with colleagues or community members. Ten out of nineteen participants (53\%) provided responses. Data collected from the mid- and final program evaluation indicate that overall, participants were highly satisfied with the program content and process. Final program evaluation and "spotlight interview" responses described various ways alumni planned to or were applying the program content to their ongoing and future work. Examples of follow-on work are provided in the next section.

\section{Empowering community leaders for sustained and meaningful engagement}

Conventional approaches to community engagement, such as workshops and community action teams, are established strategies for improving population health outcomes and health interventions [Cyril et al., 2015; O'Mara-Eves et al., 2015]. Building on the conventional approach of the ISP, Battelle and DOS developed a Mission Mosquito Communications Network and Sustainability Plan that promoted the use of social media and other forms of electronic communication to ensure continued engagement post-ISP. Social media as a tool for health communication has seen a shift from unidirectional mass dissemination of information to multidirectional, participatory dialogue between the public, researchers, and community leaders [Burnett Heldman, Schindelar and Weaver, 2013; Chou et al., 2013]. The Communications Network allowed for real-time feedback and ongoing information sharing among ISP participants and broader stakeholders. Enhancing the potential for discourse, participation, and informal learning via social media and other forms of electronic communication promotes community empowerment and extends the reach of health communication and literacy [Wals et al., 2014].

\section{Social Media for Sustained Communication}

Social media platforms, including WhatsApp and Facebook, were used to maintain communication among participants during the ISP and to encourage sustained engagement post-ISP. During the ISP, WhatsApp, a cross-platform messaging and Voice over IP service, was used to build a network among participants and for group coordination while traveling. WhatsApp is a common means of communication in many countries, as it is cheaper than SMS messages or phone calls and encryption services provide a sense of privacy over other platforms. WhatsApp is also used as a source of news and information [Ansari and Tripathi, 2017]. As an outcome of ISP discussions, a private Facebook group was also created for information sharing post-ISP. Initialization of the social media groups was facilitated by Battelle, including early messaging; however, program alumni quickly began to post to and engage on the platforms shortly thereafter. Program alumni were periodically reminded via social media platforms and email to continue to utilize both social media groups for ongoing information sharing. Engagement remained active throughout the program, although WhatsApp was used more frequently and by a wider range of participants. WhatsApp was beneficial for brief programmatic requests, and prompted info-sharing, including 
updates of relevant alumni activities. Facebook provided an additional platform to share news, events, tools, and resources that helped to supplement activities.

Battelle and DOS collaborated in the development of a social media campaign leading up to World Mosquito Day 2019 to increase awareness of the Mission Mosquito ISP outcomes and success stories. The campaign shared via DOS platforms from 1-20 August 2019, reached over 300,000 users and summarized highlights of the ISP and follow-on work. Battelle, ISP alumni, and partner networks also amplified these messages via social media.

Battelle developed a website to complement the social media campaign, which provided an overview of the ISP, highlights ISP alumni, and allowed access to ISP-related materials and products produced by alumni. Site analytics indicated most visitors were from social media, and the reach of the site extended beyond countries represented by ISP alumni and hosts, as shown in Figure 2.

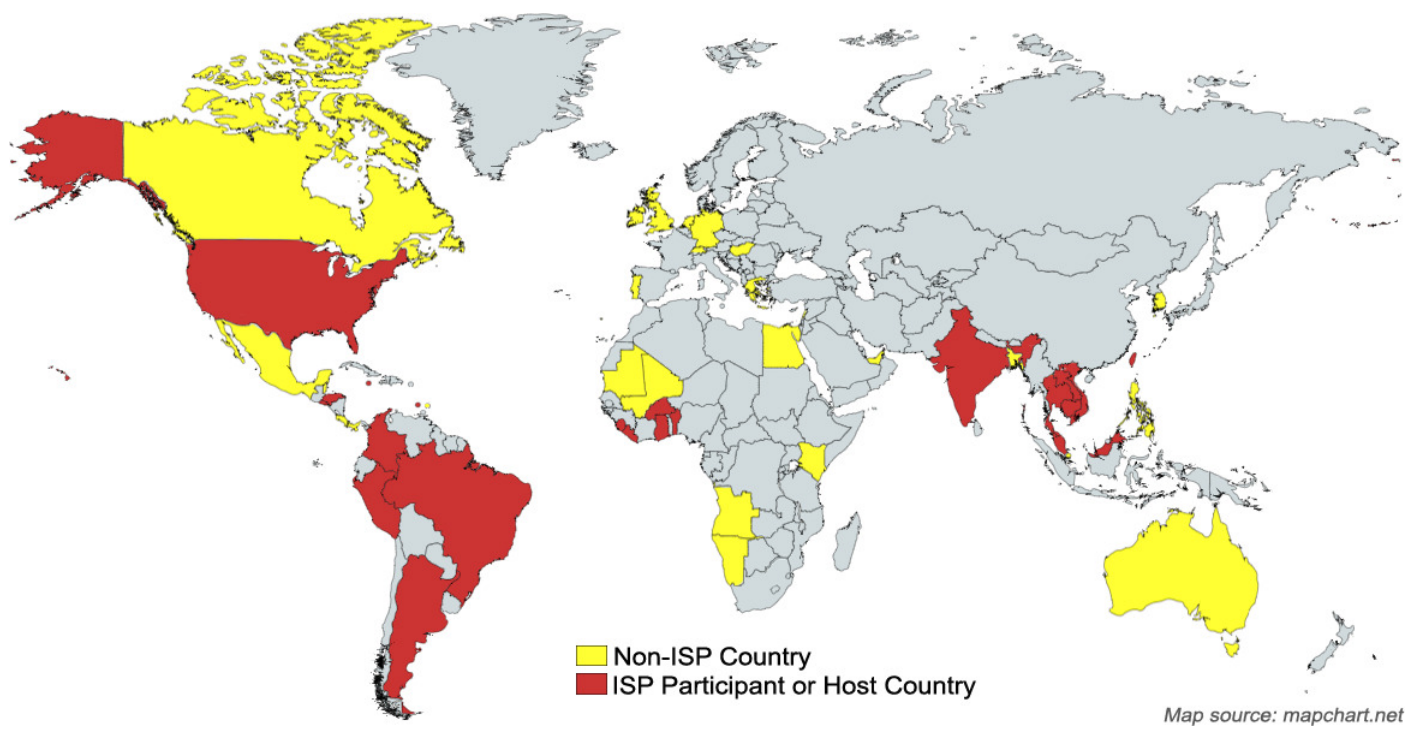

Figure 2. Website Visitors by Country (1-22 August 2019).

\section{Mission Mosquito ISP Small Grant Projects}

To foster real-world application, alumni were encouraged to not only employ new skills, approaches, or tools gained through the ISP in their routine work, but also to propose relevant pilot projects for implementation through a small grant competition held exclusively for program participants. Five small grant projects were proposed, four of which were funded and implemented during 2019:

- Community mobilization for the prevention and control of malaria and other vector-borne diseases in Kono district of Sierra Leone. This project engaged the district health management team and other key stakeholders in the development of a counseling guide and training for community health workers, health club members, and school health club members working on social behavioral change communications.

- Community-led mosquito-borne disease control initiative in Liberia. This project facilitated the development of training materials and implementation 
of "train-the-trainer" sessions for community health workers to mobilize education on mosquito-borne disease prevention and control measures, with special attention to women and children.

- Together against Zika: stakeholder video testimonials in Peru. This project supplemented an ongoing project focused on preventing mosquito-borne disease, resulting in a series of video testimonials, via YouTube, from stakeholders such as neighbors, schoolteachers, community volunteers and local, regional, and national authorities based in three northern provinces in Peru.

- Community perspectives of vector-borne disease: a nature India photo contest. This project involved a public outreach program for vector-borne disease, including a global photo contest, photo exhibitions, and supplemental discussions. Additional details of this small grant project are highlighted in the case study below.

\section{Participant Follow-on Activities}

In addition to the small grants, several alumni engaged in follow-on activities to supplement their ongoing professional roles, demonstrating sustained interest in and application of program content. Examples include:

- In Honduras, the participant fostered new relationships with non-profit organizations, USAID, and television media for a Zika campaign; planning is underway to include the Outbreak exhibition and translated Pest Fest films, a DOS sponsored film series exploring the threats caused by vector-borne diseases.

- In El Salvador, the participant leveraged a pre-existing "Zika Cluster" group of NGOs coordinating on USAID-funded activities related to mosquito-borne disease and pesticide resistance testing. The participant also created an alliance with the Smithsonian Institution to offer the Outbreak exhibit at the National Museum of Anthropology, including a mobile version of the exhibit that traveled across three cities, reaching more than 2,000 visitors.

- In the frontier region of Argentina, Brazil, and Paraguay, ISP participants engaged with the Global Learning and Observations to Benefit the Environment (GLOBE) Program ${ }^{1}$ during a Zika citizen science training promoting regional collaboration.

- In Thailand, best practices from the ISP were used to enhance National Science Museum exhibits and science education activities for the National Science Fair.

Promoting disease prevention and global health diplomacy through public engagement with community leaders: a case study

The ISP aimed to inspire participants to empower communities toward action to prevent deadly mosquito-borne diseases. Upon returning to their home countries,

\footnotetext{
${ }^{1}$ https://www.globe.gov/.
} 
four ISP participants were awarded funds to initiate participatory projects designed to facilitate informal learning and community engagement. Community engagement is crucial in modifying localized social action and health behaviors [Wallerstein et al., 2015]. Public contests, a type of crowdsourcing, are an innovative and effective approach to health communication and understanding public perceptions [Merchant et al., 2014; Mathews et al., 2018]. Photo contests, in particular, are effective at engaging public audiences beyond contest participants, and can be useful in reorienting public messaging [Zhang et al., 2017].

The Nature India Photo Contest and Exhibitions is an example of a public outreach program to raise awareness about vector-borne diseases and stifle the notion that these diseases are "the new normal". The project, which ran from October 2018 to August 2019, included a global photo contest, a traveling exhibition of the winning photos, and a series of informal discussions led by scientists and health care professionals.

The contest call for entries focused on engaging the general public, as well as scientific and health care communities, to capture images to initiate public discussions about vector-borne diseases. The call for entries was publicized on Nature India's "Indigenous" blog; there were no eligibility criteria, but entries were limited to two per person. To encourage participation, incentives were offered to the top three winners. A total of 403 contest entries were received, from which ten finalists were selected. Of the ten finalists, three winners (first, second, and third place) were selected by four Nature India representatives. The images were judged according to adherence to the theme, creativity, quality, and impact based partially on social media engagement.

The three winning photos depicted the theme from various perspectives. ${ }^{2}$ The winning image showed a child playing inside a mosquito net, highlighting the potential simplicity of prevention methods for dengue, malaria, and other mosquito-borne diseases. The second-place image showed a close-up of an Aedes aegypti mosquito, displaying the beautiful zebra-like coloring. In his description, the photographer noted the complexity of ecosystems, recognizing that complete eradication of mosquitoes might bring other detrimental effects. Lastly, the third-place photo is a close-up of a mosquito taking a blood meal on the hand of an individual with a description of the juxtaposition between the scale of a mosquito bite and the potential gravity of disease.

The three winning photos and the remaining seven finalist photos were printed and framed for inclusion in a traveling exhibition held at six venues in India, reaching over 5,000 people. Images were also showcased on the Nature India website and featured in the 2018 Nature India annual print volume. With a readership of over one million, Nature India expects the photos will reach new readers as they are shared into the future and online presence will continue to expand reach. The project was innovative in encouraging photographers to consider mosquito-borne diseases through a visual lens. Further, using visual images to educate the public or raise awareness ensures the content is accessible to wide audiences of various ages and educational backgrounds.

\footnotetext{
${ }^{2}$ http:/ / blogs.nature.com/indigenus / 2019/01/announcing-the-winners-of-ni-photo-contest2018.html.
} 
Summary of

Lessons Learned and Conclusions
During the ISP, key discussion points confirmed several key best practices for health communications. Additionally, a number of lessons learned were gleaned from the program that participants could apply in continuing their work to increase awareness of mosquito-borne disease and prevention measures worldwide. Other organizations can also leverage these lessons learned in implementing similar capacity building efforts in the future.

- The six principles of crisis and emergency response communication, or CERC (be first; be right; be credible; act with empathy; focus on action; and act with respect), can serve as a foundation for developing and implementing health communication. However, it is important to recognize that communication during crises differs from routine communications, as the public may take in, process, and act on information differently than in day-to-day situations. ISP participants noted that the introduction to CERC training was particularly beneficial and relevant to the work that they conduct. Nonetheless, many also indicated that additional more in-depth training, including real-world examples, would have been beneficial. Any real-world examples should focus on the issue at hand (e.g. infectious disease outbreaks versus more general health risks) given important nuances in communication for different types of risks or emergencies.

- Communicate what is known, recognize gaps in knowledge or understanding, and if complete information is unavailable, acknowledge it and discuss efforts underway to continue to find additional information. Balancing response efforts and research during an emergency can be challenging, particularly when there is a need for additional information, as demonstrated by the uncertainties regarding microcephaly and Guillain-Barré Syndrome cases during the Zika outbreak.

- It is critical for communicators to understand public perceptions and misinformation that may be circulating. Real-world challenges and opportunities regarding vector control efforts in various communities were offered by ISP participants. For example, some ISP participants discussed the range of community reactions to the use or non-use of insecticide spraying, noting in some instances community resistance when spraying occurs. Efforts to increase public awareness of the risks and benefits of spraying could potentially help to alleviate public concerns when vector-control measures must be taken to protect public health.

- Identifying the audience and tailoring messages in personalized and contextualized ways is crucial, as is disseminating communication through platforms that meet audiences' informational needs. In terms of personalizing risk messaging in a way that resonates, program participants learned that during Zika outreach efforts in Miami, the public was more receptive when there was a focus on the risk to babies. However, men with certain occupational risk factors (e.g., construction workers around mosquito breeding sites) were at increased risk and not taking preventive measures to lower exposure.

- Social media can be a powerful tool for public communication; however, such platforms also have key limitations. Interactions with public health communicators during the ISP highlighted that social media should only be 
used if resources for maintaining timely communications on these platforms can be secured, particularly during emergencies such as a vector-borne disease outbreak when timely information is critical. Further, while social media offers a platform for proliferating rumors or false claims, it can also serve as an effective mechanism to address misinformation. Lastly, not all target audiences may have access to or rely on social media for communication, requiring multiple mechanisms to reach various subpopulations. For example, some ISP participants, particularly in West Africa, travel to remote communities for community health work, where access to social media may be limited, if available at all. Other participants work with older adult populations, who also may not access social media.

- Intersectoral coordination is critical for success, particularly for complex environmental health issues like mosquito-borne diseases, which require interdisciplinary engagement among state and local government, health organizations, and mosquito control and public works. Although it can be difficult and time-consuming, establishing and maintaining relationships between government offices, media, the public, and other organizations during non-emergency situations can also offer efficiencies when an emergency does occur. Additionally, as participants saw in South Florida, establishing consistent messaging across governmental agencies can minimize public confusion or misinformation and result in more effective prevention of - or response to - public health risks.

\section{Implications for future projects}

The Mission Mosquito ISP is an effective example of how a capacity building approach emphasizing experiential learning and multi-directional information sharing can lead to an empowered, self-sustaining global network of professionals, such as health communicators. Several key components of the implementation approach were particularly crucial for success and could be replicated or improved upon in future projects related to building capacity to address other public health threats or communication needs.

\section{- The composition of the participant cohort can offer both benefits and} challenges to program planning and implementation. Our cohort was designed to include scientists, community health experts, and communication staff from Ministries of Health, newspaper and television media, a science publication, a national science museum, and other NGOs. While this diversity in professional roles offered a rich assortment of perspectives and experiences to build upon during discussions, it also added complexity in selecting topics to prioritize during the limited time together. For example, in Colorado, a handful of participants were highly engaged and interested in the more technical discussions and tours of the insectary lab and field station where research is conducted, while other participants with less scientific backgrounds expressed that this was the least interesting content of the ISP. A benefit of maintaining a diverse participant group is providing exposure to new topics outside of any individuals' expertise. Additionally, this diversity offers opportunities for learning best practices for engaging with others as part of an optimal response team during an outbreak, 
including coordinating to develop clear and scientifically accurate messages. Alternatively, limiting future cohorts to a more homogenous group (e.g., media) could allow for more in-depth exploration and dialogue on a more targeted range of topics with greater direct relevance to each participant. Additionally, the cohort included participants from across 19 countries, with varying levels of English proficiency. While the nomination criteria specified demonstration of a certain level of English proficiency, one or two participants periodically struggled with understanding and potentially did not benefit as much from the program if that language barrier did not exist. Opportunities for relationship building and informal information exchange are limited if participants do not all have an equal level of language proficiency. Given resource constraints and other practical limitations of this type of program, the use of translation services to mitigate this challenge was impossible as this would have required the procurement of interpretation services at each stop or additional travel funding for interpretation staff. Future programs could proactively require more formalized confirmation of language proficiency or explore feasibility of translation options, if necessary.

- The ISP ensured active engagement between participants and public and private sector experts through facilitated trainings, site tours, presentations, small-group discussions, and field visits. As the most significant component of the overall Mission Mosquito project, the ISP was a successful example of a multi-directional information exchange and opportunity for experiential public health engagement. This approach, emphasizing the sharing of unique perspectives and experiences, allowed participants to learn from each other and consider applications that would maximize effectiveness within their own situational and cultural contexts.

- The facilitation of a small grant competition encouraged innovative application of the knowledge, skills, tools, and networks acquired during the ISP via follow-on activities. Successful capacity building empowers leaders to take ownership of interventions designed to engage community members in minimizing health risk and provide customized training and informational materials to meet the needs of the participants' communities in an innovative and evidence-based manner. Community engagement and buy-in is central to changing behaviors and overall sustainability of prevention efforts. While there was a limited number of applicants for the small grants, those that were implemented were successful in supplementing vector-borne disease communication and education activities. Additional evaluation of why interest was limited could be conducted and modifications could be made (e.g., increase funding amounts, offer proposal writing support) to increase engagement in future programs.

- Social media was a key component in building relationships and ensuring ongoing engagement among program participants. Utilization of WhatsApp and Facebook for group updates, information sharing, and recognition of successes was critical in establishing bonds between participants both during and after the ISP. Additional electronic media, such as the program website, blog site, and YouTube, offered platforms to increase awareness of the program and the participants, and to celebrate successful implementation of activities in health promotion. Increased emphasis and dedication of resources on such electronic tools for future programs could further enhance internal and external communication and engagement. 
In conclusion, the discussion themes and lessons learned from the ISP provided a foundation for program alumni to apply communication best practices in their ongoing work to help in the prevention of mosquito-borne disease. These practices can also be applied more broadly to health communication activities on other topics as well. Furthermore, the capacity building approach utilized in the planning and implementation of this program and lessons learned can be replicated, customized, and improved upon to serve broader health and science communication needs worldwide.

Disclaimer. The views expressed are those of the authors and not of the U.S. Government.

Acknowledgments Funding for this work was made possible by DOS through cooperative agreement award SLMAQM17CA2072. The authors would like to thank our DOS partners, including Kia Henry, Susan Cleary, David Maurice Jones, Daniel Tripp, Josh Glasser and others who supported the program. The authors also thank Battelle ISP co-facilitators Katie LeVan and Martin Alvarado, and colleagues Clayton Clark, Meredith Fritz, and Amanda Morgan. Finally, the authors would like to acknowledge and thank the 19 Mission Mosquito ISP alumni.

\section{References}

Ansari, M. S. and Tripathi, A. (2017). 'Use of WhatsApp for effective delivery of library and information services'. DESIDOC Journal of Library $\mathcal{E}$ Information Technology 37 (5), p. 360. https://doi .org/10.14429/djlit.37.5.11090.

Brittain, A. W., August, E. M., Romero, L., Sheahan, M., Krashin, J., Ntansah, C., Honein, M. A., Jamieson, D. J., Ellis, E. M., Davis, M. S. and Lathrop, E. (2019). 'Community perspectives on contraception in the context of the Zika virus in the U.S. Virgin Islands: implications for communication and messaging'. Women's Health Issues 29 (3), pp. 245-251. https://doi.org/10.1016/j.whi.2019.01.007.

Burnett Heldman, A., Schindelar, J. and Weaver, J. B. (2013). 'Social media engagement and public health communication: implications for public health organizations being truly 'social'. Public Health Reviews 35 (1), pp. 1-18. https://doi.org/10.1007/bf03391698.

Cardenas, V. M., Paternina-Caicedo, A. J. and Salvatierra, E. B. (2019). 'Underreporting of fatal congenital Zika syndrome, Mexico, 2016-2017'. Emerging Infectious Diseases 25 (8), pp. 1560-1562. https://doi.org/10.3201/eid2508.190106.

Chou, W.-Y. S., Prestin, A., Lyons, C. and Wen, K.-Y. (2013). 'Web 2.0 for health promotion: reviewing the current evidence'. American Journal of Public Health 103 (1), e9-e18. https://doi .org/10.2105/ajph.2012.301071.

Cyril, S., Smith, B. J., Possamai-Inesedy, A. and Renzaho, A. M. N. (2015). 'Exploring the role of community engagement in improving the health of disadvantaged populations: a systematic review'. Global Health Action 8 (1), 29842. https://doi.org/10.3402/gha.v8.29842.

Gage, K. L., Burkot, T. R., Eisen, R. J. and Hayes, E. B. (2008). 'Climate and vectorborne diseases'. American Journal of Preventive Medicine 35 (5), pp. 436-450. https://doi.org/10.1016/j.amepre.2008.08.030. 
Grubaugh, N. D., Saraf, S., Gangavarapu, K., Watts, A., Tan, A. L., Oidtman, R. J., Ladner, J. T., Oliveira, G., Matteson, N. L., Kraemer, M. U. G., Vogels, C. B. F., Hentoff, A., Bhatia, D., Stanek, D., Scott, B., Landis, V., Stryker, I., Cone, M. R., Kopp, E. W., Cannons, A. C., Heberlein-Larson, L., White, S., Gillis, L. D., Ricciardi, M. J., Kwal, J., Lichtenberger, P. K., Magnani, D. M., Watkins, D. I., Palacios, G., Hamer, D. H., Gardner, L. M., Perkins, T. A., Baele, G., Khan, K., Morrison, A., Isern, S., Michael, S. F. and Andersen, K. G. (2019). 'Travel surveillance and genomics uncover a hidden Zika outbreak during the waning epidemic'. Cell 178 (5), 1057-1071.e11.

https://doi.org/10.1016/j.cell.2019.07.018.

Horstick, O., Runge-Ranzinger, S., Nathan, M. B. and Kroeger, A. (2010). 'Dengue vector-control services: how do they work? A systematic literature review and country case studies'. Transactions of the Royal Society of Tropical Medicine and Hygiene 104 (6), pp. 379-386.

https://doi.org/10.1016/j.trstmh.2009.07.027.

Maciel-de-Freitas, R., Aguiar, R., Bruno, R. V., Guimarães, M. C., Lourenço-de-Oliveira, R., Sorgine, M. H. F., Struchiner, C. J., Valle, D., O'Neill, S. L. and Moreira, L. A. (2012). 'Why do we need alternative tools to control mosquito-borne diseases in Latin America?' Memórias do Instituto Oswaldo Cruz 107 (6), pp. 828-829. https://doi.org/10.1590/s0074-02762012000600021.

Mathews, A., Farley, S., Hightow-Weidman, L., Muessig, K., Rennie, S. and Tucker, J. D. (2018). 'Crowdsourcing and community engagement: a qualitative analysis of the 2BeatHIV contest'. Journal of Virus Eradication 4 (1), pp. 30-36. PMID: 29568551.

McNeish, R., Rigg, K. K., Tran, Q. and Hodges, S. (2019). 'Community-based behavioral health interventions: developing strong community partnerships'. Evaluation and Program Planning 73, pp. 111-115. https://doi.org/10.1016/j.evalprogplan.2018.12.005.

Merchant, R. M., Griffis, H. M., Ha, Y. P., Kilaru, A. S., Sellers, A. M., Hershey, J. C., Hill, S. S., Kramer-Golinkoff, E., Nadkarni, L., Debski, M. M., Padrez, K. A., Becker, L. B. and Asch, D. A. (2014). 'Hidden in plain sight: a crowdsourced public art contest to make automated external defibrillators more visible'. American Journal of Public Health 104 (12), pp. 2306-2312. https://doi.org/10.2105/ajph.2014.302211.

O'Mara-Eves, A., Brunton, G., Oliver, S., Kavanagh, J., Jamal, F. and Thomas, J. (2015). 'The effectiveness of community engagement in public health interventions for disadvantaged groups: a meta-analysis'. BMC Public Health 15 (1), pp. 1-23. https://doi .org/10.1186/s12889-015-1352-y.

Pan American Health Organization (PAHO) (2019). Cases of Zika virus disease. URL: http://www . paho.org/data/index .php/en/?option=com_content\&view =article\&id=524\&Itemid= (visited on 26th August 2019).

Siedner, M. J., Ryan, E. T. and Bogoch, I. I. (2018). ‘Gone or forgotten? The rise and fall of Zika virus'. The Lancet Public Health 3 (3), e109-e110. https://doi.org/10.1016/s2468-2667(18)30029-x.

Wallerstein, N., Minkler, M., Carter-Edwards, L., Avila, M. and Sánchez, V. (2015). 'Improving health through community engagement, community organization and community building'. In: Health behavior: theory, research and practice. Ed. by K. Glanz, B. K. Rimer and K. V. Viswanath. San Francisco, CA, U.S.A.: Jossey-Bass, pp. 277-300. 
Wals, A. E. J., Brody, M., Dillon, J. and Stevenson, R. B. (2014). ‘Convergence between science and environmental education'. Science 344 (6184), pp. 583-584. https://doi.org/10.1126/science.1250515.

World Health Organization (WHO) (2014). A global brief on vector-borne diseases. WHO report WHO/DCO/WHD/2014.1. URL: https://apps . who.int/iris/handle/10665/111008 (visited on 6th November 2019).

- (31st October 2017). Vector-borne diseases. WHO fact sheets. URL: https : //www.w ho. int/news-room/fact-sheets/detail/vector-borne-diseases (visited on 28th August 2019).

- (2019a). ‘Global overview'. In: WHO Zika epidemiology update, July 2019, pp. 1-14. URL: https://www. who. int/emergencies/diseases/zika/epidemiol ogy-update/en/.

- (2019b). 'Zika: the continuing threat'. Bulletin of the World Health Organization 97 (1), pp. 6-7. https://doi.org/10.2471/BLT.19.020119.

Zhang, W., Schaffer, D., Tso, L. S., Tang, S., Tang, W., Huang, S., Yang, B. and Tucker, J. D. (2017). 'Innovation contests to promote sexual health in China: a qualitative evaluation'. BMC Public Health 17 (1), pp. 1-7. https://doi.org/10.1186/s12889-016-4006-9. Columbus, $\mathrm{OH}$. She brings an interdisciplinary approach to projects, often working at the intersection of health and societal impacts of global environmental change. Working to improve broader understanding of relationships between the built and natural environment and public health, she plans and implements stakeholder-engaged research, multi-directional information exchanges, and develops and disseminates decision-support and public outreach tools.

E-mail: maslak@battelle.org.

Kia Henry is a Public Diplomacy Officer in the Bureau of Oceans and International Environmental and Scientific Affairs (OES) at the U.S. Department of State. She uses communication and outreach to inspire audiences about science diplomacy and environmental issues ranging from outer space to the sea floor. She manages NASA's GLOBE program and is program manager for global public outreach projects including Mission Mosquito and the GLOBE Zika Education and Prevention Project. She also contributes content to @SciDiplomacyUSA. E-mail: henrykt@state.gov.

Natasha Sadoff is a Principal Research Scientist at Battelle Memorial Institute. Her interdisciplinary work is focused on human-environment interactions and emphasizes the social and public health impacts of environmental change, development and urbanization, or pollutants. She brings this perspective to topics such as climate change adaptation and resilience; energy management; air quality; solid waste management; and improving environmental governance through stakeholder needs assessments, user engagement, training and outreach, and capacity building or development. E-mail: sadoffn@battelle.org. 
David Maurice Jones is a former Foreign Service Officer with the U.S. Department of State. Serving in various roles while at the Department, David's Foreign Service career centered around diplomacy programming related to educational and cultural exchange, as well as community engagement and development. Outside of the Department, David's career has focused on volunteerism, community service, and human development. E-mail: davidmaurice.jones@gmail.com.

Joshua Glasser, M.S., is a Foreign Affairs Officer at the U.S. Department of State's Office of International Health and Biodefense, where he is focused on health security and the global environment. He works on a variety of human-animal-environmental health ("One Health") issues, including in the Arctic, the Asia-Pacific, and India, and in the context of the Global Health Security Agenda and the World Health Organization. Mr. Glasser joined the State Department as a Presidential Management Fellow in 2013. E-mail: glasserj@@state.gov.

Amy Leibrand is a Principal Research Scientist at Battelle Memorial Institute in Columbus, $\mathrm{OH}$. Her area of focus spans the nexus of public health and the environment, including capacity building and science communication for non-technical audiences. Her primary work supports the end use of Earth observation data with the aim to bridge the gap between cutting-edge science and real-world applications for the benefit of society. Ms. Leibrand is a member of the American Geophysical Union. E-mail: leibranda@battelle.org.

\section{How to cite}

Maslak, T. M., Henry, K., Sadoff, N., Jones, D. M., Glasser, J. L. and Leibrand, A. (2020). 'Mission Mosquito: building and expanding an international network for innovation in health communication'. JCOM 19 (03), N01. https:/ / doi.org/10.22323/2.19030801. 